\title{
AGROMETEOROLOGIA
}

Nota

\section{TEMPERATURA MÍNIMA LETAL PARA PLANTAS JOVENS \\ DE PINHÃO-MANSO $\left({ }^{\mathbf{1}}\right)$}

\author{
GISELLY APARECIDA ANDRADE (2); PAULO HENRIQUE CARAMORI $\left({ }^{3}\right)$; FÁBIO SUANO DE SOUZA $\left({ }^{3}\right)$; \\ CELSO JAMIL MARUR $\left({ }^{3}\right)$; ANA MARIA DE ARRUDA RIBEIRO $\left(\left(^{*}\right)\right.$
}

\begin{abstract}
RESUMO
O objetivo deste trabalho foi determinar a temperatura mínima letal em plantas jovens de Pinhãomanso (Jatropha curcas L.), visando à expansão desta cultura no sul do Brasil como alternativa para produção de biodiesel. O experimento foi desenvolvido no Instituto Agronômico do Paraná (IAPAR), em Londrina (PR) a $23^{\circ} 23^{\prime} \mathrm{S}, 50^{\circ} 11^{\prime} \mathrm{W}$. Em uma câmara fria, foram realizados tratamentos com temperaturas mínimas de $+1{ }^{\circ} \mathrm{C}, 0{ }^{\circ} \mathrm{C},-1{ }^{\circ} \mathrm{C},-2{ }^{\circ} \mathrm{C},-3{ }^{\circ} \mathrm{C},-4{ }^{\circ} \mathrm{C}$ e $-5{ }^{\circ} \mathrm{C}$, comparados com um controle exposto à temperatura ambiente. O delineamento estatístico foi inteiramente casualizado, com 10 repetições. As variáveis avaliadas foram: taxa fotossintética das plantas após 6 horas, 7 e 14 dias; danos foliares visuais um dia e um mês após os tratamentos, mortalidade das plantas um mês após os tratamentos e recuperação das plantas no campo. De acordo com as observações, a temperatura mínima letal para o pinhão-manso está entre $-3{ }^{\circ} \mathrm{C}$ e $-4{ }^{\circ} \mathrm{C}$.
\end{abstract}

Palavras-chave: biodiesel, estresse térmico, geada, dano foliar, fotossíntese, câmara fria.

\section{ABSTRACT \\ MINIMUM LETHAL TEMPERATURE FOR SEEDLINGS OF THE OIL SEED PLANT}

The objective of this paper was to determine the minimum lethal temperature for the oil seed plant Jatropha curcas L., aiming at supporting the expansion of this crop in southern Brazil as an alternative for biofuel production. The experiment was carried out at the Agronomic Institute of Paraná (IAPAR), in Londrina-PR $\left(23^{\circ} 23^{\prime} \mathrm{S}, 50^{\circ} 11^{\prime} \mathrm{W}\right)$. In a cold chamber environment, young plants were submitted to treatments with minimum temperatures of $+1{ }^{\circ} \mathrm{C}, 0{ }^{\circ} \mathrm{C},-1{ }^{\circ} \mathrm{C},-2{ }^{\circ} \mathrm{C},-3{ }^{\circ} \mathrm{C},-4{ }^{\circ} \mathrm{C}$ and $-5{ }^{\circ} \mathrm{C}$, and compared to a control exposed to ambient temperature. Ten plants in each test (replications) were distributed within the chamber in a completely randomized design. The following parameters were evaluated: photosynthetic rate after 6 hours and 7 and 14 days; visual foliar damages one day and one month after the tests; plant mortality one month after the tests and plant recovering in the field. The minimum lethal temperature for Jatropha curcas is between $-3{ }^{\circ} \mathrm{C}$ and $-4{ }^{\circ} \mathrm{C}$.

Key words: biofuel, thermal stress, frost, foliar damage, photosynthesis, cold chamber.

$\left({ }^{1}\right)$ Recebido para publicação em 2 de julho de 2007 e aceito em 8 de janeiro de 2008.

$\left({ }^{2}\right)$ Estudante de pós-graduação em Agronomia Universidade Estadual de Londrina. E-mail: giselly@iapar.br

$\left({ }^{3}\right)$ Instituto Agronômico do Paraná, Rodovia Celso Garcia Cid, km 375, Três Marcos, Caixa Postal 481, 86047-902 Londrina (PR). E-mail: caramori@iapar.br, fssouza@iapar.br ; cjmarur@iapar.br

$\left({ }^{4}\right)$ Departamento de Agronomia, Universidade Estadual de Londrina, Rodovia Celso Garcia Cid, km 380, Campus Universitário, Caixa Postal 6001, 86051-990 Londrina (PR). E-mail: arruda@uel.br $\left(^{*}\right)$ Autor correspondente. 


\section{Introdução}

Biodiesel é a denominação genérica para combustíveis e aditivos derivados de fontes renováveis (Holanda, 2004). É produzido a partir de óleos vegetais puros ou usados e de gorduras animais, em que ocorre reação com álcool (etanol ou metanol), chamada reação de transesterificação, resultando em compostos conhecidos como ésteres de ácidos graxos (etílicos ou metílicos) (Miragaya, 2005). É um combustível que permite o estabelecimento de um ciclo fechado de carbono no qual absorve-se o $\mathrm{CO}_{2}$ quando a planta cresce e liberado quando o biodiesel é queimado na combustão do motor (YAMAOKA et al., 2005). Dezenas de espécies vegetais oleaginosas no Brasil podem ser utilizadas na produção de biodiesel e, dentre elas, o pinhão-manso tem se destacado como planta rústica, perene e adaptável a uma vasta gama de ambientes e condições edafoclimáticas (SATURNINO et al., 2005). Sua distribuição geográfica é bastante vasta, podendo ser encontrada desde o Nordeste brasileiro até os Estados de São Paulo e do Paraná (CORTESÃo, 1956).

Por ser pouco exigente em relação ao clima e solo, adapta-se facilmente a variadas condições. Contudo, não tolera geadas fortes, mas pode sobreviver a geadas fracas, com queda de folhas e redução na produção de sementes (SATURNINO et al., 2005).

Com vistas a estudar a viabilidade do cultivo no Sul do Brasil, o objetivo deste trabalho foi determinar a temperatura mínima letal para plantas jovens de Pinhão-manso (Jatropha curcas L.) visando à expansão desta cultura no sul do Brasil como alternativa para a produção de biodiesel.

O experimento foi desenvolvido no Instituto Agronômico do Paraná (IAPAR), em Londrina (PR). A temperatura média anual no município é de $21^{\circ} \mathrm{C}$, sendo a média do mês mais quente (janeiro) de $24^{\circ} \mathrm{C}$ e a média do mês mais frio (junho) $17^{\circ} \mathrm{C}$ (CAviglione et al., 2000). Em novembro de 2005, sementes de pinhão-manso (Jatropha curcas L.) foram mantidas em caixa de areia por 10 dias e após este período, transplantadas em saquinhos plásticos de $15 \times 35 \mathrm{~cm}$, contendo substrato $(40 \%$ solo argiloso $+40 \%$ areia + $15 \%$ esterco de curral $+5 \%$ de superfosfato simples). As mudas foram mantidas em viveiro e em junho de 2006, transferidas para uma casa de vegetação para serem protegidas das baixas temperaturas durante $o$ inverno, onde foram mantidas até o momento de aplicação dos tratamentos (2 a 3 meses), quando tinham aproximadamente $40 \mathrm{~cm}$ de altura e em média 10 folhas por planta. Para a simulação das temperaturas mínimas, utilizou-se uma câmara de crescimento, referência comercial Conviron, modelo CMP 3244. As plantas foram acondicionadas na área útil de teste e submetidas às seguintes temperaturas mínimas: $1{ }^{\circ} \mathrm{C}, 0{ }^{\circ} \mathrm{C},-1{ }^{\circ} \mathrm{C},-2{ }^{\circ} \mathrm{C},-3{ }^{\circ} \mathrm{C},-4{ }^{\circ} \mathrm{C}$ e $-5^{\circ} \mathrm{C}$. Um lote de plantas foi mantido na casa de vegetação como testemunha.

A programação da câmara foi feita de forma que reproduzisse as condições naturais, baseando-se em uma situação real de geada. A luminosidade no interior da câmara foi programada para simular um dia de aproximadamente 12 horas. A irradiância fotossintética partiu de zero às 6 horas e atingiu 123 $\mu$ mol. $\mathrm{m}^{-2} . \mathrm{s}^{-1}$ às $6: 30 \mathrm{~h}, 429 \mu \mathrm{mol} . \mathrm{m}^{-2} . \mathrm{s}^{-1}$ às 10 horas, 573 $\mu \mathrm{mol} . \mathrm{m}^{-2} . \mathrm{s}^{-1}$ às 12 horas e mantendo este valor até as 14 horas, decrescendo a partir de então até atingir o valor zero por volta das 18 horas. As plantas foram acondicionadas no interior da câmara por volta das 12 horas e passaram por um período de aclimatização de quatro horas a $15^{\circ} \mathrm{C}$, com $60 \%$ de umidade relativa. Depois da aclimatização, a temperatura foi reduzida linearmente atingindo a mínima, aproximadamente, após 10 horas.

A temperatura mínima foi mantida por uma hora, voltando a subir até atingir equilíbrio aos $15^{\circ} \mathrm{C}$ após 4 horas, quando as plantas foram transferidas para uma casa de vegetação. A temperatura no interior da câmara foi monitorada por meio de sete sensores de termopar (cobre-constantan), distribuídos entre as plantas na altura destas e ligados a um coletor automático de dados, conforme método utilizado por Morais et al. (2003). A umidade se elevou conforme o decréscimo da temperatura, atingindo valores próximos à saturação no momento da temperatura mínima, de acordo com o observado por SiLVA (2004).

Seis horas depois de levadas para a casa de vegetação (por volta das 14 horas), realizaram-se as medições da fotossíntese das plantas, utilizando-se um analisador de gás portátil (LI-COR, modelo LI6200); procedeu-se, também, à contagem de plantas cujas folhas estavam mortas após os tratamentos. Essas avaliações foram repetidas aos sete e quatorze dias após o experimento.

As plantas foram mantidas em casa de vegetação por um mês, quando foi feita nova avaliação da porcentagem de plantas sobreviventes. Em seguida, foram transplantadas para o campo, onde foi avaliada sua recuperação por meio de medições de fotossíntese e de avaliações visuais do vigor vegetativo.

O delineamento estatístico foi o inteiramente casualizado, com 10 repetições, sendo sete tratamentos de temperaturas mínimas às quais as plantas foram submetidas e uma testemunha sem estresse térmico. Os dados de fotossíntese obtidos foram submetidos à 
análise de regressão a 5\% de significância. As médias foram comparadas utilizando o teste de Tukey $(\mathrm{P}<0,05)$.

A variação da temperatura monitorada com pares termoelétricos em sete pontos da câmara foi inferior a $0,5^{\circ} \mathrm{C}$, caracterizando uma condição de ambiente satisfatória para realização do estudo. Para os dados de fotossíntese, a regressão polinomial quadrática foi significativa $(\mathrm{P}<0,0001)$ nas leituras feitas 6 horas e sete dias após a aplicação dos tratamentos, indicando a existência de relação causal entre a temperatura mínima e a fotossíntese da planta. Os coeficientes de determinação $\left(R^{2}=0,73\right)$ para 6 horas após a aplicação do tratamento e $\left(\mathrm{R}^{2}=0,83\right)$ para 7 dias após, revelam que grande parte da variação da fotossíntese pode ser explicada pela variação da temperatura mínima aplicada nos tratamentos. Nas leituras de fotossíntese, feitas 14 dias após a aplicação dos tratamentos a regressão não foi significativa, com $\mathrm{R}^{2}=0,16$, demonstrando que após a primeira semana as plantas sobreviventes recuperaram-se, exibindo taxas fotossintéticas similares à testemunha.

Os valores médios de fotossíntese variaram de $-0,9 \mu \mathrm{mol} \mathrm{CO}_{2} \mathrm{~m}^{-2} \mathrm{~s}^{-1}$ no tratamento $-5^{\circ} \mathrm{C}$ a 8,8 $\mu \mathrm{molCO}_{2} \mathrm{~m}^{-2} \mathrm{~s}^{-1}$ no controle, considerando as leituras feitas 6 horas após os tratamentos (Tabela 1). Na leitura feita 7 dias após os tratamentos, os valores variaram de $1,1 \mu \mathrm{mol} \mathrm{CO} 2 \cdot \mathrm{m}^{-2} \cdot \mathrm{s}^{-1}$ no tratamento $-4{ }^{\circ} \mathrm{C}$ a $15,7 \mu \mathrm{mol} \mathrm{CO} \mathrm{CO}_{2} \mathrm{~m}^{-1}$ no tratamento $-1{ }^{\circ} \mathrm{C}$. Aos catorze dias após os testes, os valores variaram de 6,9 $\mu \mathrm{mol} \mathrm{CO} \mathrm{CO}^{-2} \mathrm{~s}^{-1}$ no controle a $13,4 \mu \mathrm{mol} \mathrm{CO} \mathrm{Cm}^{-2} \mathrm{~s}^{-1}$ no $-2{ }^{\circ} \mathrm{C}$. Em plantas de pinhão-manso, quando submetidas às temperaturas -3 e $-4{ }^{\circ} \mathrm{C}$, houve diminuição na taxa fotossintética de 6 horas e 7 dias após o estresse. No entanto, após 14 dias, houve recuperação das plantas e as taxas fotossintéticas medidas foram superiores aos demais tratamentos, incluindo o controle. Este comportamento demonstrou que o estresse, quando não atingiu o nível letal, provocou nas plantas um aumento na taxa fotossintética em relação àquelas sem estresse tão severo. Esses dados são indicativos de que plantas de pinhão-manso diminuem sua fotossíntese perante estresse, porém, possuem ajustamento do aparato fotossintético a fim de recuperar tal diminuição em momentos posteriores ao estresse, ocasionando ganho compensatório em relação ao tratamento-controle.

Em plantas que passaram pelos tratamentos $+1{ }^{\circ} \mathrm{C}, 0{ }^{\circ} \mathrm{C},-1{ }^{\circ} \mathrm{C}$ e $-2{ }^{\circ} \mathrm{C}$ não ocorreram danos visíveis em suas folhas (Figura 1). No tratamento $-3{ }^{\circ} \mathrm{C}, 60 \%$ das plantas tiveram todas as suas folhas mortas pelo frio, enquanto a $-4^{\circ} \mathrm{C}$ e $-5^{\circ} \mathrm{C}$, além de terem todas as folhas mortas, houve danos também nos caules. A - 3
${ }^{\circ} \mathrm{C}$ alguns fatores podem ter determinado que em $40 \%$ das plantas não tenha sido visível qualquer dano. A concentração de açúcares no suco celular ou o status hídrico da planta podem contribuir para que haja variabilidade nos danos em temperaturas próximas aos valores letais. Diversos autores constatam que em plantas expostas a temperaturas críticas, mesmo acima do ponto de congelamento, pode haver danos foliares letais, dependendo da idade dos tecidos, condição nutricional, aclimatação e tempo de exposição (BAUER et al.,1985; BODNER e LARCHER, 1987).

Tabela 1. Médias de fotossíntese nas leituras feitas 6 horas, 7 e 14 dias após os tratamentos

\begin{tabular}{|c|c|c|c|}
\hline \multirow{2}{*}{ Tratamento } & \multicolumn{3}{|c|}{ Fotossíntese (Dias após tratamento) } \\
\hline & 6 horas & 7 dias & 14 dias \\
\hline & \multicolumn{3}{|c|}{$\mu \mathrm{molCO}_{2} \mathrm{~m}^{-2} \mathrm{~s}^{-1}$} \\
\hline Controle & 8,8 a & $8,6 \mathrm{~b}$ & $6,9 \mathrm{a}$ \\
\hline$+1^{\circ} \mathrm{C}$ & $4,5 \mathrm{bc}$ & $14,1 \mathrm{a}$ & 9,4 a \\
\hline $0^{\circ} \mathrm{C}$ & $7,3 \mathrm{ab}$ & $12,6 \mathrm{ab}$ & 11,9 a \\
\hline$-1^{\circ} \mathrm{C}$ & $4,2 \mathrm{~cd}$ & 15,7 a & 11,3 a \\
\hline$-2^{\circ} \mathrm{C}$ & $5,5 \mathrm{bc}$ & $14,2 \mathrm{a}$ & 13,4 a \\
\hline$-3^{\circ} \mathrm{C}$ & $2,4 \mathrm{~d}$ & $4,4 \mathrm{c}$ & 13,3 a \\
\hline$-4^{\circ} \mathrm{C}$ & $-0,92 \mathrm{e}$ & $1,1 \mathrm{c}$ & $10,6 \mathrm{a}$ \\
\hline$-5^{\circ} \mathrm{C}$ & $-0,9$ e & mortas & Mortas \\
\hline
\end{tabular}

As médias seguidas de mesma letra nas colunas não diferem entre si pelo Teste de Tukey a $5 \%$ de probabilidade.

Após um mês em casa de vegetação, nos tratamentos $+1{ }^{\circ} \mathrm{C}, 0{ }^{\circ} \mathrm{C},-1{ }^{\circ} \mathrm{C},-2{ }^{\circ} \mathrm{C}$ e $-3{ }^{\circ} \mathrm{C} 100 \%$ das plantas estavam vegetando; no tratamento $-4{ }^{\circ} \mathrm{C}$ somente $40 \%$ das plantas sobreviveram e emitiram novas folhas; no $-5^{\circ} \mathrm{C}$ não houve sobreviventes. Comparando-se os resultados das porcentagens de plantas cujas folhas estavam mortas um dia após os tratamentos, com a porcentagem de plantas vivas um mês após os tratamentos, observa-se que as plantas do tratamento $-3{ }^{\circ} \mathrm{C}$ tiveram $100 \%$ de recuperação, e no tratamento $-4{ }^{\circ} \mathrm{C}$ apenas $40 \%$ conseguiram se recuperar. Portanto, fica evidente que o limiar de dano por geadas situa-se entre $-3{ }^{\circ} \mathrm{C} \mathrm{e}-4{ }^{\circ} \mathrm{C}$. Este limite é semelhante ao da cultura do café, estimado em torno de $-3,4^{\circ} \mathrm{C}$ (CAmargo e Salatti, 1967; Ferraz, 1968), com variações dependendo do tempo de exposição ao frio (MANETTI e CARAMORI, 1986) ou da condição da planta (CARAMORI et al., 2001).

Aproximadamente um mês após os tratamentos, quando foram levadas ao campo, nas plantas não havia diferença nas taxas fotossintéticas entre os tratamentos. No campo não foram observadas diferenças visuais nem fotossintéticas entre os tratamentos. 

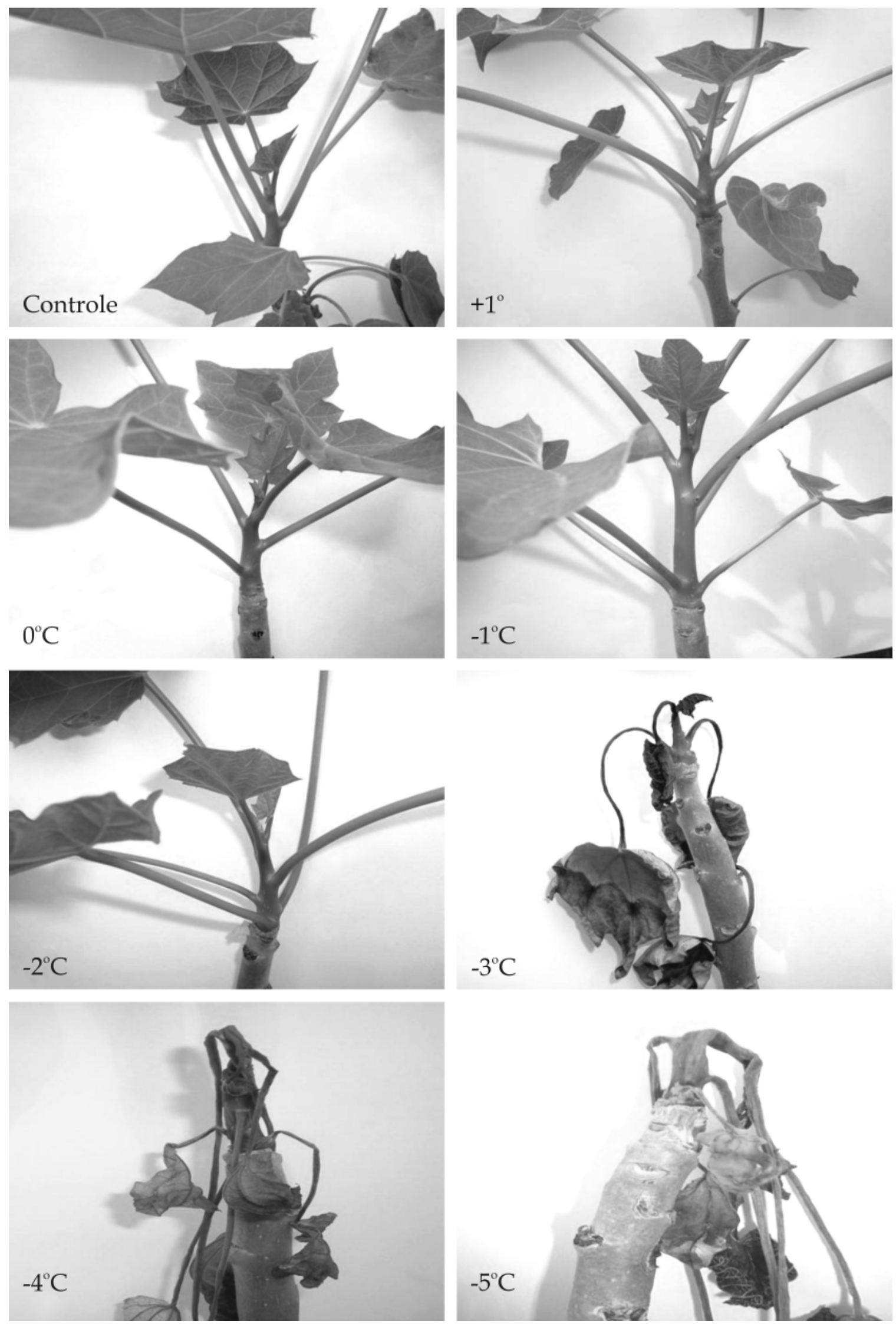

Figura 1. Plantas-jovens de Pinhão-manso (Jatropha curcas L.) sete dias após serem submetidas às temperaturas mínimas $+1{ }^{\circ} \mathrm{C}, 0{ }^{\circ} \mathrm{C},-1{ }^{\circ} \mathrm{C},-2{ }^{\circ} \mathrm{C},-3{ }^{\circ} \mathrm{C},-4{ }^{\circ} \mathrm{C},-5^{\circ} \mathrm{C}$ e tratamento controle em temperatura ambiente. 
O fato de ser uma planta adaptada a ambientes de baixa umidade pode conferir maior tolerância ao frio ao pinhão-manso. Embora possam ocorrer danos foliares por baixas temperaturas, a excelente recuperação das plantas revelou que a presença de gemas dormentes, mais tolerantes que os tecidos foliares, proporciona tolerância a temperaturas mais baixas.

Pode-se concluir que a temperatura mínima crítica para o cultivo de plantas jovens de pinhãomanso (Jatropha curcas L.) está entre $-3{ }^{\circ} \mathrm{C} \mathrm{e}-4{ }^{\circ} \mathrm{C}$, em condições de ambiente controlado e que estas possuem grande capacidade de recuperação de danos causados por temperaturas acima de $-3^{\circ} \mathrm{C}$.

\section{REFERÊNCIAS}

BAUER, H. et al. Photosynthesis of Coffea Arabica after chilling. Physiologia Plantarum, Copenhagen, v.64, p.449-454, 1985.

BODNER, M.; LARCHER, W. Chilling susceptibility of different organs and tissues of Saintpaulia ionantha and Coffea arabica. Botany, Berlin, v. 61, p. 225-242, 1987.

CAMARGO, A.P.; SALATI, E. Determinación de la temperatura letal para hojas de café en noches de heladas. Café, Lima, v.8, n. 3, p.12-15,1967.

CARAMORI, P.H.; CAVIGLIONE, J.H.;, WREGE, M.S.; GONÇALVES, S. L.; FARIA, R. T.; ANDROCIOLI FILHO, A.; SERA, T.; CHAVES, J.C.D.; KOGUISHI, M. S. Zoneamento de riscos climáticos para a cultura de café (Coffea arabica L.) no Estado do Paraná. Revista Brasileira de Agrometeorologia, Passo Fundo, v.9, n.3, p. 486-494, 2001.

CORTESÃO, M. Culturas tropicais: plantas oleaginosas. Lisboa: Clássica, 1956. 231p.

CAVIGLIONE, J. H.; CARAMORI, P. H.; KIIHL, L. B; OLIVEIRA, D. Cartas Climáticas do Paraná. Londrina: IAPAR, 2000. (CD-ROM)

FERRAZ, E. C. Estudos sobre o momento em que a geada danifica as folhas do cafeeiro. 1968. Tese (Doutorado em Agronomia) - Escola Superior de Agricultura Luiz de Queirós - USP, Piracicaba,

HOLANDA, A. Biodiesel e inclusão social. Brasília: Câmara dos Deputados, Coordenação de Publicações, 2004. 200p.

MANETTI FILHO, J.; CARAMORI, P.H. Desenvolvimento de uma câmara para simulação de temperaturas baixas. Pesquisa Agropecuária Brasileira, Brasília, v.21, n.10, p.1005-1008, 1986.

MIRAGAYA, J. C. G. Biodiesel: tendências no mundo e no Brasil. Informe Agropecuário, Belo Horizonte, v.26, n. 229, p.7-13, 2005.
MORAIS, H. Efeito do sombreamento de cafeeiros (Coffea arabica L.) com guandu (Cajanus cajan (L) Millsp.) no norte do Paraná. 2003. 118 p. Dissertação. (Mestrado em Agronomia) - Universidade Estadual de Londrina - UEL, Londrina.

SATURNINO, H.M.; PACHECO, D.D.; KAKIDA, J.; NAGASHI, T.; GONÇALVES, N.P. Cultura do pinhão-manso (Jatropha curcas L.). Informe Agropecuário, Belo Horizonte, v.26, n. 229, p.44-78, 2005.

SILVA, M.A.A.; GALVANI, E.; ESCOBEDO, J.F.; Avaliação de elementos meteorológicos durante a ocorrência de geada em cultivo de pimentão, nas condições de ambiente protegido e campo. Revista Brasileira de Agrometeorologia, Santa Maria, v.12, n.1, p. 35-41, 2004.

YAMAOKA, R.S.; COSTA, A.; SOUZA, R.; FAUCZ, R.; OLIVEIRA, D. Programa Paranaense de Bioenergia - "PR Bioenergia". In: CONGRESSO BRASILEIRO DE PLANTAS OLEAGINOSAS, ÓLEOS, GORDURAS E BIODIESEL, 2., 2005, Varginha. Anais... Varginha: Universidade Federal de Lavras e Prefeitura Municipal de Varginha, 2005, p. 912-916. 